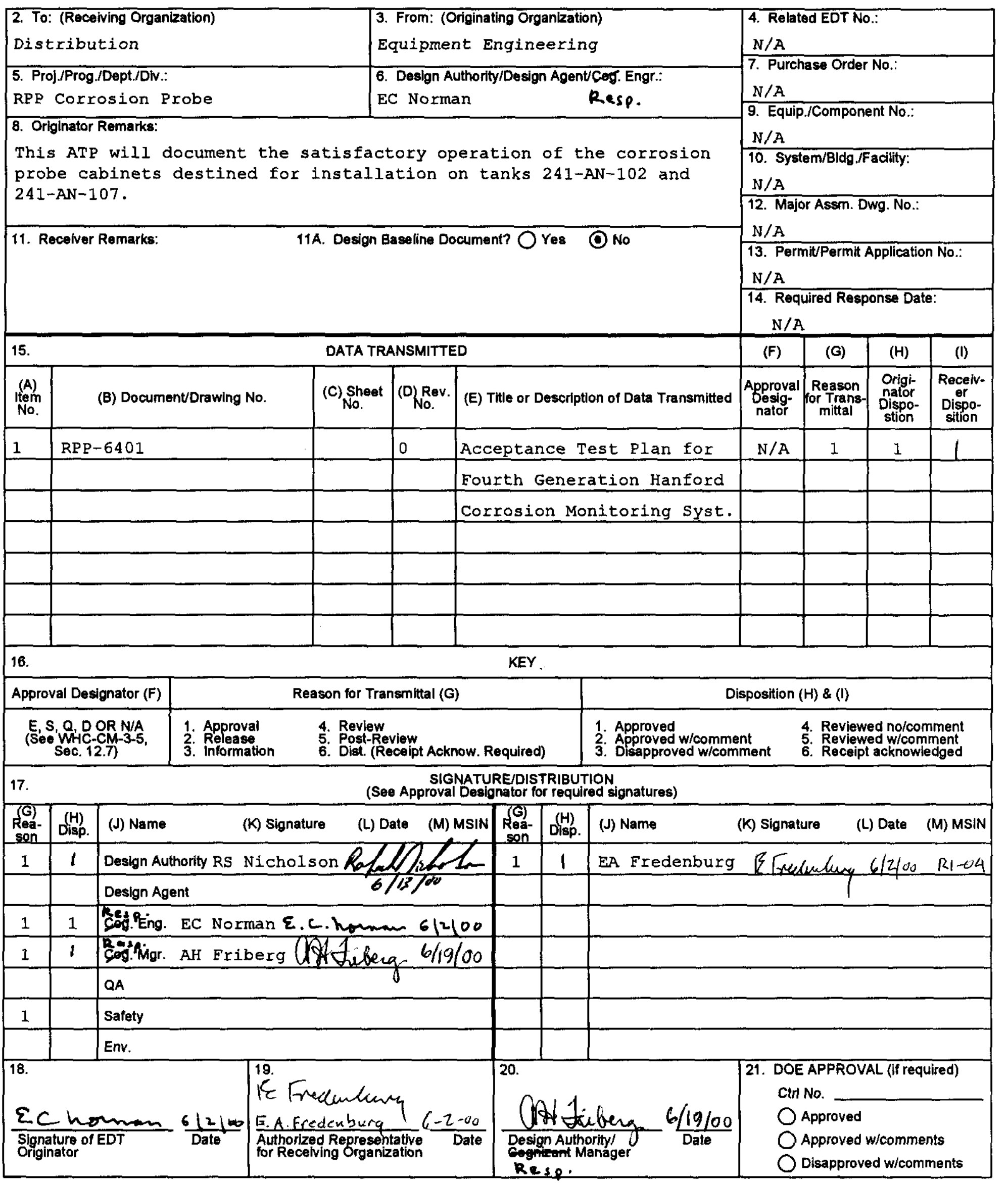




\section{Acceptance Test Plan for Fourth Generation Hanford Corrosion Monitoring System}

E. C. Norman

CH2M HILL Hanford Group, Inc.

Richland, WA 99352

U.S. Department of Energy Contract DE-AC06-96RL13200

EDT/ECN: 629678

UC: 2030

Org Code: 74700

B\&R Code: EW4010000

Charge Code: 112671

Total Pages:

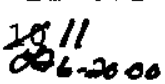

Key Words: corrosion monitoring, corrosion probe

Abstract: This Acceptance Test Plan (ATP) will document the satisfactory operation of the corrosion probe cabinets destined for installation on tanks 241-AN-102 and 241-AN-107.

TRADEMARK DISCLAIMER. Reference herein to any specific commercial product, process, or service by trade name, trademark, manufacturer, or otherwise, does not necessarily constitute or imply its endorsement, recommendation, or favoring by the United States Government or any agency thereof or its contractors or subcontractors.

Printed in the United States of America. To obtain copies of this document, contact: Document Control Services, P.O. Box 950, Mailstop H6-08, Richland WA 99352, Phone (509) 372-2420; Fax (509) 376-4989.
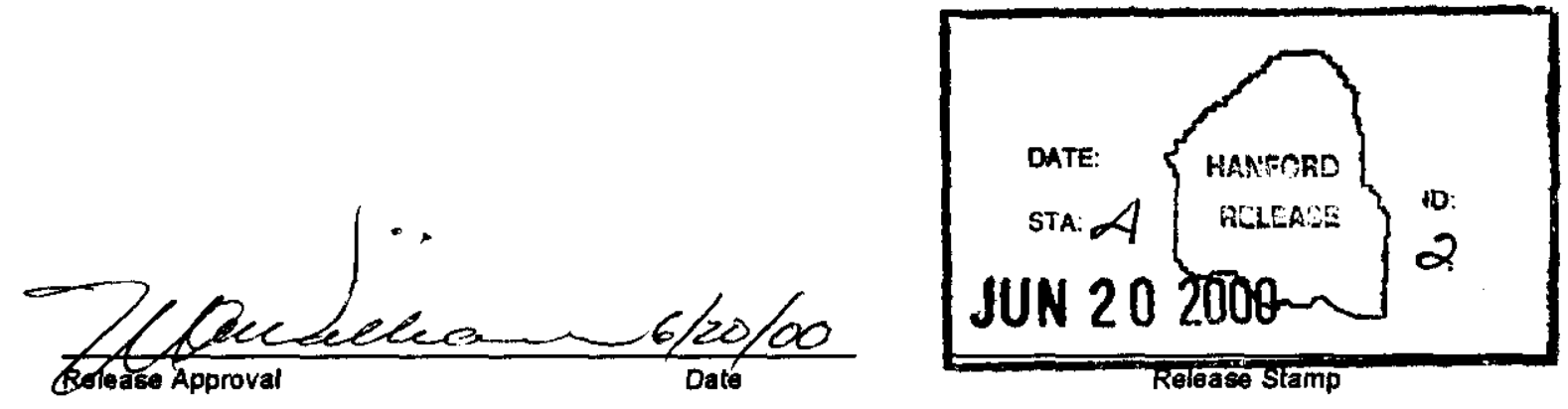

Approved For Public Release 
RPP-6401, Rev. 0

\title{
ACCEPTANCE TEST PLAN FOR FOURTH GENERATION HANFORD CORROSION MONITORING SYSTEM
}

\author{
G. L. Edgemon \\ Hiline Engineering \& Fabrication, Inc. \\ 2105 Aviator Drive \\ Richland, Washington 99352
}


RPP-6401, Rev. 0

\section{ACCEPTANCE TEST PLAN FOR FOURTH GENERATION \\ HANFORD CORROSION MONITORING SYSTEM}

\subsection{PURPOSE}

This Acceptance Test Plan (ATP) will document the satisfactory operation of the corrosion probe cabinets destined for installation on tanks 241-AN-102 and 241-AN-107. This ATP will be performed by the manufacturer on each cabinet prior to delivery to the site.

\subsection{TEST OBJECTIVES}

The objective of this procedure is to demonstrate and document the acceptance of the corrosion monitoring cabinets to be installed on tanks 241-AN-102 and 241-AN-107. One cabinet will be installed on each tank. Each cabinet will contain corrosion monitoring hardware to be connected to existing corrosion probes already installed in each tank. The test will consist of a continuity test of the cabinet wiring from the end of cable to be connected to corrosion probe, through the appropriate intrinsic safety barriers and out to the 15 pin D-shell connectors to be connected to the corrosion monitoring instrument. Additional testing will be performed using a constant current and voltage source provided by the corrosion monitoring hardware manufacturer to verify proper operation of corrosion monitoring instrumentation (input a known signal and see if the instrumentation records the proper value).

\subsection{RESPONSIBILITIES}

\subsection{TEST COORDINATION AND PERFORMANCE}

A representative from $\mathrm{CH} 2 \mathrm{M}$ Hill Hanford Group's Equipment Engineering organization or designee shall be responsible for the coordination, scheduling, performance, and documentation of this test procedure.

\subsection{TEST WITNESSES}

A representative from CH2M Hill Hanford Group's Equipment Engineering organization or designee shall perform the function of test witness. All corrosion probe tree assembly testing shall be witnessed, verified and approved with the Test Engineers signature.

\subsection{RECEIPT INSPECTION}

Cabinets will be subjected to receipt inspection and inspection by a certified National Electric Code (NEC) inspector from the appropriate organizations within the Hanford Site prior to acceptance by the Hanford Site. 
RPP-6401, Rev. 0

\subsection{DOCUMENTATION}

\subsection{TEST RECORD}

Any personnel involved in the performance of this test including the Test Engineer shall fill out a line in Section 7.0 RECORDS.

Test results shall be recorded by the Test Engineer. Unacceptable conditions or readings are to be referred to Section 8.0 EXCEPTIONS. A complete working copy of this procedure and all exception records shall be maintained as lifetime records in accordance with RPP-PRO222, Rev. 0, Quality Assurance Records Standards.

\subsection{EXCEPTIONS}

Exceptions by step number, and other notes are to be recorded under Section 8.0 EXCEPTIONS. This section must be dispositioned (including the generation of any required ECNs) and signed off by the Test Engineer prior to final ATP acceptance. If no exceptions are encountered, this section shall be so noted and closed out with the signature of the Test Engineer. During the performance of this test errors in text may be encountered which require correction/adjustment to complete the test. The correction is to be noted in the ATP and listed as an exception in Section 8.0 EXCEPTIONS.

\subsection{TEST EXECUTION RECORD}

Approval of the ATP results shall be accepted by the Test Engineer as indicated by signature in Section 9.0 TEST EXECUTION RECORD.

\subsection{TEST EQUIPMENT}

- Multimeter

- Constant Voltage/Current Source

\subsection{ACCEPTANCE TEST}

Complete acceptance test procedure is to be performed on each cabinet.

\subsection{CONTINUITY TEST}

Using a standard multimeter, electrical continuity shall be verified on each of the 24 conductors used for picking up signal from corrosion probe electrodes. To perform this continuity check, make the necessary connections between each pin on the connector that will be attached to the existing corrosion probe and its respective pin in the 15 pin D-type connector that will be attached to the corrosion monitoring hardware. Use the data cable that will be used in the final field installation for this test. The continuity check will be 
RPP-6401, Rev. 0

performed starting with channel 1 , and ending with channel 8 . 
6.1.1 Record model, serial number, and calibration expiration date of multimeter below.

Instrument: SN:

Calibration Expiration Date:

6.1.2 Check continuity on each channel of Cabinet \#1. Circle Yes or No in regard to whether continuity exists.

Conductor

Channel 1 Working Electrode

Channel 1 Counter Electrode

Channel 1 Reference Electrode

Channel 2 Working Electrode

Channel 2 Counter Electrode

Channel 2 Reference Electrode

Channel 3 Working Electrode

Channel 3 Counter Electrode

Channel 3 Reference Electrode

Channel 4 Working Electrode

Channel 4 Counter Electrode

Channel 4 Reference Electrode

Channel 5 Working Electrode

Channel 5 Counter Electrode

Channel 5 Reference Electrode

Channel 6 Working Electrode

Channel 6 Counter Electrode

Channel 6 Reference Electrode

Channel 7 Working Electrode

Channel 7 Counter Electrode

Channel 7 Reference Electrode

Channel 8 Working Electrode

Channel 8 Counter Electrode

Channel 8 Reference Electrode
Continuity

Yes/No

Yes/No

Yes/No

$\mathrm{Yes} / \mathrm{No}$

Yes/No

Yes/No

Yes/No

Yes/No

Yes/No

Yes/No

Yes/No

Yes/No

Yes/No

Yes/No

Yes/No

Yes/No

Yes/No

Yes/No

Yes/No

Yes/No

Yes/No

Yes/No

Yes/No

$\mathrm{Yes} / \mathrm{No}$ 
6.1.3 Check continuity on each channel of Cabinet \#2. Circle Yes or No in regard to whether continuity exists.

\begin{tabular}{|c|c|}
\hline Conductor & Continuity \\
\hline Channel 1 Working Electrode & Yes/No \\
\hline Channel 1 Counter Electrode & Yes/No \\
\hline Channel 1 Reference Electrode & Yes/No \\
\hline Channel 2 Working Electrode & Yes/No \\
\hline Channel 2 Counter Electrode & Yes/No \\
\hline Channel 2 Reference Electrode & Yes/No \\
\hline Channel 3 Working Electrode & Yes/No \\
\hline Channel 3 Counter Electrode & Yes/No \\
\hline Channel 3 Reference Electrode & Yes/No \\
\hline Channel 4 Working Electrode & Yes/No \\
\hline Channel 4 Counter Electrode & Yes/No \\
\hline Channel 4 Reference Electrode & Yes/No \\
\hline Channel 5 Working Electrode & Yes/No \\
\hline Channel 5 Counter Electrode & Yes/No \\
\hline Channel 5 Reference Electrode & Yes/No \\
\hline Channel 6 Working Electrode & Yes/No \\
\hline Channel 6 Counter Electrode & Yes/No \\
\hline Channel 6 Reference Electrode & Yes/No \\
\hline Channel 7 Working Electrode & Yes/No \\
\hline Channel 7 Counter Electrode & Yes/No \\
\hline Channel 7 Reference Electrode & Yes/No \\
\hline Channel 8 Working Electr & Yes/No \\
\hline Channel 8 Counter $\mathrm{E}$ & Yes/No \\
\hline Channel 8 Reference Electrode & Yes/No \\
\hline
\end{tabular}

6.1.4 Test Engineer sign that steps 6.1.1 through 6.1.3 are complete.

Test Engineer Date

\subsection{INSTRUMENTATION FUNCTIONAL TEST}

Using a constant current and constant voltage source of between $0.1-20$ microamps and 0.1 
to $200 \mathrm{mV}$ respectively, check operation of corrosion monitoring instrumentation by putting instrumentation in measuring configuration and properly measuring/recording the known signal provided by the source. Constant current and voltage source should be checked for accuracy with calibrated multimeter prior to start of testing. Constant current and voltage source should be measured by corrosion monitoring software/hardware using the actual cables to be used in the final field installation. Constant current and voltage source should be measured after passing through the intrinsic safety barrier system to be used in final field installation.

Connect constant current/voltage source to appropriate pins at end of data cable to be connected to corrosion probe in final field installation. This cable should run back through the intrinsic safety barriers and be properly connected to corrosion monitoring instrumentation per vendor instruction. Launch corrosion monitoring software and record on each channel for a minimum of one minute to verify that known current/voltage signal is being properly recorded by software. Test will be considered a success on each channel if that channel records values within $+/-10 \%$ of the source values for current and voltage.

6.2.1 Record model, serial number, and calibration expiration date of multimeter below.

Instrument: $\mathrm{SN}:$

Calibration Expiration Date:

6.2.2 Record model and serial number of constant current/voltage source below. Instrument: SN:

6.2.3 Check known constant current/voltage signal against measured current/voltage value on corrosion monitoring software/hardware on Cabinet $\# 1$.

$\begin{array}{lllll}\text { Channel } & \begin{array}{l}\text { Constant } \\ \text { Current } \\ \text { Source } \\ \text { Value }\end{array} & \begin{array}{l}\text { Constant } \\ \text { Voltage } \\ \text { Source } \\ \text { Value }\end{array} & \begin{array}{l}\text { Instrument } \\ \text { Recorded } \\ \text { Current } \\ \text { Value }\end{array} & \begin{array}{l}\text { Instrument } \\ \text { Recorded } \\ \text { Voltage } \\ \text { Value }\end{array} \\ & - & - & -\end{array}$


RPP-6401, Rev. 0

4

5

6

7

8

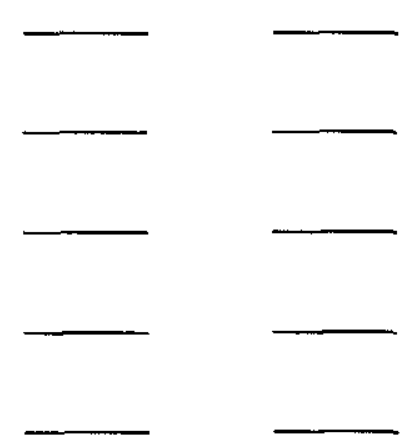

6.2.4 Check known constant current/voltage signal against measured current/voltage value on corrosion monitoring software/hardware on Cabinet \#2.

\begin{tabular}{|c|c|c|c|c|}
\hline Channel & $\begin{array}{l}\text { Constant } \\
\text { Current } \\
\text { Source } \\
\text { Value }\end{array}$ & $\begin{array}{l}\text { Constant } \\
\text { Voltage } \\
\text { Source } \\
\text { Value }\end{array}$ & $\begin{array}{l}\text { Instrument } \\
\text { Recorded } \\
\text { Current } \\
\text { Value }\end{array}$ & $\begin{array}{l}\text { Instrumen } \\
\text { Recorded } \\
\text { Voltage } \\
\text { Value }\end{array}$ \\
\hline 1 & & & & \\
\hline 2 & & & & \\
\hline 3 & & & & \\
\hline 4 & & & & \\
\hline 5 & & & - & - \\
\hline 6 & & 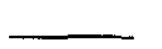 & _ & בــ \\
\hline 7 & & & 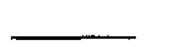 & - \\
\hline 8 & & & & \\
\hline
\end{tabular}

6.2.5 Test Engineer sign that steps 6.2.1 through 6.2.4 are complete.

Test Engineer Date




\subsection{RECORDS}

TEST ENGINEER

Test Engineer Sign In:

Test Engineer Date

TEST WITNESSES

Print Name

Signature

Position

Date

\subsection{EXCEPTIONS}

\begin{tabular}{|l|l|l|l|}
\hline ITEM & STEP & DESCRIPTION & DISPOSITION \\
\hline & & & \\
\hline & & & \\
\hline & & & \\
\hline
\end{tabular}

TEST APPROVED WITH/WITHOUT EXCEPTIONS (CIRCLE WITH OR WITHOUT):

Test Engineer

$$
\text { Date }
$$




\subsection{TEST EXECUTION RECORD}

\begin{tabular}{|l|l|l||}
\hline Section & Accept/Reject & Remarks \\
\hline 6.1 & & \\
& & \\
\hline \hline 6.2 & & \\
\hline
\end{tabular}

Test Engineer

Date 


\section{DISTRIBUTION SHEET}

To

Distribution

Project Title/Work Order

RPP-6401, Acceptance Test Plan for Fourth Generation Hanford Corrosion Monitoring System

\begin{tabular}{|c|c|c|c|c|c|}
\hline Name & MSIN & $\begin{array}{c}\text { Text } \\
\text { With All } \\
\text { Attach. }\end{array}$ & Text Only & $\begin{array}{l}\text { Attach.I } \\
\text { Appendix } \\
\text { Only }\end{array}$ & $\begin{array}{c}\text { EDT/ECN } \\
\text { Only }\end{array}$ \\
\hline EA Fredenburg & $\mathrm{R} 1-04$ & $x$ & & & \\
\hline EC Norman & $\mathrm{R} 1-04$ & $x$ & & & \\
\hline RS Nicholson & $55-05$ & $x$ & & & \\
\hline JL Castleberry & $R 1-56$ & $\mathrm{x}$ & & & \\
\hline GL Edgemon & $R 3-83$ & $x$ & & & \\
\hline & & & & & \\
\hline & & & & & \\
\hline & & & & & \\
\hline & & & & & \\
\hline & & & & & \\
\hline & & & & & \\
\hline & & & & & \\
\hline & & & & & \\
\hline & & & & & \\
\hline & & & & & \\
\hline & & & & & \\
\hline & & & & & \\
\hline & & & & & \\
\hline & & & & & \\
\hline & & & & & \\
\hline & & & & & \\
\hline & & & & & \\
\hline & & & & & \\
\hline & & & & & \\
\hline & & & & & \\
\hline & & & & & \\
\hline & & & & & \\
\hline & & & & & \\
\hline & & & & & \\
\hline & & & & & \\
\hline & & & & & \\
\hline
\end{tabular}

From

Equipment Engineering

Page 1 of 1

Date June 2, 2000

EDT No. 629678

ECN No. 